\title{
Thinking about water and air to attain Sustainable Development Goals during times of COVID-19 Pandemic
}

\author{
Abhistt Mukherjee ${ }^{1, *} \oplus, \mathrm{S}$ Suresh $\mathrm{Babu}^{2}$ and Subimal Ghosh ${ }^{3}$ \\ ${ }^{1}$ Applied Policy Advisory in Hydrosciences (APAH) Group, Department of Geology and Geophysics, and School of \\ Environmental Science and Engineering, Indian Institute of Technology, Kharagpur 721 302, India. \\ ${ }_{3}^{2}$ Space Physics Laboratory, Vikram Sarabhai Space Centre, Thiruvananthapuram 695 022, India. \\ ${ }^{3}$ Department of Civil Engineering, Indian Institute of Technology Bombay, Powai, Mumbai 400 076, India. \\ ${ }^{*}$ Corresponding author.e-mail: amukh2@gmail.com abhijit@gg.iitkgp.ac.in
}

MS received 17 June 2020; revised 8 August 2020; accepted 11 August 2020; published online 29 August 2020

In 2020, we are in the doorstep of a new decade, during which the UN Sustainable Development Goals (SDG) are to be achieved, collectively as one nation and one human-hood, where availability of safe, sustainable and clean water and air forms the core of multiple goals. However, the emergence of the COVID-19 pandemic across the globe has resulted a newer challenge and paradigm for an evolving socioscientific priorities. It is generally expected that the impacts of the pandemic would be in shorter timescale, while the planned time and pathway for attaining the SDG are typically mandated in longer-term, hence may remain mostly unaffected. However, the stringent lockdown measures, isolated economies and financial burden to contain the pandemic emergency have resulted to slowdown of socio-economic development, which if continues for a longer period, would put a question mark on developing plans and pathways to achieve the SDGs, even in decadal-scale. Hence, in these newer times, it is important to understand the real priorities of availability of clean water and air, which are already stressed worldwide and in India, because of various natural and human-influenced triggers. This ongoing pandemic has provided an unprecedented opportunity to evaluate the impact of human development and consequent feedback of nature and human society in pre- and post-COVID scenarios on water-air-human life, which can help to re-think and re-orient the societal development priorities. It is a rare opportunity for scientists to impress the policy-makers with real-time examples on the efficacies of potential mitigation strategies for climate change, water and air pollution, and the importance of enduring investment on environmental causes and consequent benefits that can secure health and development for our future generations.

Keywords. COVID-19; SARS-COV2; water; air; pollution; SDG.

\section{Introduction}

The year 2020 began with a pandemic of unassailable global scale. The emergence of the unprecedented and unexpected pathogen, COVID-19, has transformed life to a new normal. As the pathogen has started spreading, it has reached every continent except possibly Antarctica and infecting more than 22 million people and causing about 800,000 deaths (up to the time of finalizing this article, mid-August, 2020). Consequently, across the world, the primary interest for research and research funding have now re-oriented to find a remedy for this indisputable worldwide emergency, and research in most other topics have understandably taken a back seat. Most scientific 
organizations across the world, who are not actively involved in essential research (e.g., COVID-19 remedy) and services, have to be locked-down or suspend field and laboratory research activities, leaving many of scientists' work in an indeterminate state (Chakraborty and Maity 2020).

However, this year-2020 pandemic is not only a global public health emergency, but also has huge socio-economic-environmental ramification, in both short and long run, specifically impacting the attainment of Sustainable Development Goals (SDG) across globe. The 17 goals prescribed in the charter of UN SDG, adopted in 2015 and to be achieved by 2030 , tries thread between the natural environment (natural resources, ecosystems, pollution, climate), the economy (economic growth, jobs, living standards) and society (poverty eradication, food security, promotion of equity, gender equality, human rights, peace and justice, etc). These three main facets of sustainable development (ecology, economy and society) have become known as the 'triple bottom line'. The UN had declared 2020-2030 as the 'Decade of Action' to pursue the sustainable development by addressing these three 'pillars' and striking a balance among them.

However, in 2020, while we are in the doorstep of this new decade, to achieve the SDGs, collectively as one world and one human-kind, this unexpected health crisis hit the world with fallout of overwhelming economic impact and regional polarization. The pandemic has resulted in formation of closed borders, minimal international migration and isolated economics (Arora 2020). Initial estimates indicated that the global economy may shrink by $1 \%$ in 2020 (UN 2020a); however, later projections demonstrate a possibility of reduction of global GDP by up to $5.2 \%$, which is the largest contraction in economic activity since the Great Depression (UN 2020b). The future of the extent and methods of restriction of industrial, economic and human activities would determine the severity of this financial debacle, limiting it to a moderate recession or lead to a long-term deep recession that will reflect the fiscal responses to the crisis (UN 2020a).

Phenomena like environmental pollution and climate change may occur at much slower rate than a pandemic, but if not mitigated, over period of time it may pose a more extensive risk of human survival (Srinivasan 2020). In a business-as-usual scenario, it may be envisaged that the direct impact of the pandemic possibly would be in the shorter term, while the vision of sustainable development is a long-term goal. Thus the pandemic may potentially delay the process of attaining these goals, but the paths to achieve these goals may not alter much. However, the unprecedented financial burden imposed by the pandemic, has resulted in slowdown of unexpected socio-economic developments, which if continues for a longer period, might influence development priorities and pathways to achieve the SDGs, even in decadal-scale.

This unforeseen crisis has successfully exposed the fundamental weaknesses in our global system. It has shown how a lack of global co-operation in poverty, education, health and environment can exacerbate the crisis (Solberg and Akufo-Addo 2020). The crisis is causing immense loss of human life in real-time; however, its long term effect on the pathways of sustainable development and the global economy can be disastrous. Through multiple pathways of political, socio-economic and environmental routes, the pandemic may impact global development and achieving the SDGs in catastrophic proportion (Arora 2020). The pandemic is envisioned to severely impact on most of the SDGs in short and long term, with India potentially facing major challenges in 10 of the 17 SDGs (Pandey 2020). Globally, in the year 2020, at least 71 million people might plunge in extreme poverty; more severe impacts are expected in the low-income countries and to the socio-economically vulnerable population (Lafortune et al. 2020) like that in South Asia. Consequently, in impending future, an obvious impact is expected in impeding the dream of accessing clean water (SDG 6) and air (SDG 13) in a unified world.

The objective of this paper is to highlight the need to nurture and continue investment in the environmental sustainability priorities, specifically in accessing the clean water and air, and climate change, even in post-COVID world that may have potentially diverted priorities from pre-conceived pathways. This is truer for a 'developing' country like India, which aspires to be 'developed' in the impending years, but still records some of the highest number of deaths in the world due to environmental pollution (Landrigan et al. 2018). At present, India hosts one of the major shares of global population that lacks access to clean drinking water and sanitation (Sorensen et al. 2016), as well as have few of the worst air-polluted megacities (Cohen et al. 2005). Thus, policy makers may 
have to be more resilient over the ongoing socioeconomic changes, and be prudent in distributing resources for achieving short-term milestones along with incubation of long-term goals for sustainability of the future generations.

\section{Access to clean water and sanitation during and after pandemic}

Globally, several experts and planners hoped that the pandemic may get halted with the expectancy of lower transmission capability of the virus during summer heat. Notwithstanding any expected seasonal behaviour of the virus transmission, or not, the summer months are vicious in India for its greater than ever water crisis. Unfortunately, even as the hot summer is reeling through India and Northern Hemisphere, there is unabated increase of infection. This coincides with severe drinking water stress showing up in different parts of the country.

Access to clean drinking water and sanitation are regarded as the core of sustainable development. More than half of the global population, mostly in economically-stressed areas, South Asia, Africa and other developing parts of the world, still lack access to clean water for drinking and proper sanitation (Mukherjee et al. 2019). Further, unsafe disposal of fecal and other wastes from improper sanitation to nearby drinking water sources severely endanger public health. In India $>100,000$ people die annually from water-borne diseases like diarrhea, cholera, typhoid, etc. (Duttagupta et al. 2019). Through different pathway, COVID-19 can also transmit like these aforesaid water-borne diseases in times of access to clean water are limited. The pandemic exacerbated the difficulties in achieving clean water and sanitation targets in many parts of the world (Solberg and Akufo-Addo 2020). However, the pandemic-induced lockdown also provided some short-term benefits that also needs mentioning. Reports of water quality improvement for both ground and surface water are getting documented. For example, the Vembanad Lake, the longest freshwater lake in India witnessed the suspended particulate matter concentrations for April 2020 to be reduced by 1/3rd from previous year and was documented a record low within preceding 7 years (Yunus et al. 2020). In the coastal city of Tuticorin, $\sim 50 \%$ reduction in concentrations of groundwater-borne cationic solutes, e.g., Se, As, Fe and $\mathrm{Pb}$, as well as $\mathrm{NO}_{3}$, total and fecal coliform were documented, possibly as an outcome of reduction in decreased industrial activities and waste water discharge (Selvam et al. 2020).

Clean water in India is mostly sourced to groundwater, with more than $75 \%$ of the country's domestic water sectors and $80 \%$ of irrigation being reliant on groundwater. It is well-known by now that a large part of India is living beyond its available, usable water resources. Abstraction of the 'largest groundwater volume in human history' in India for irrigation and domestic use has led to 'groundwater drought', caused by overdraft across major parts of India (Mukherjee 2018). Estimates suggest that India's remaining usable groundwater storage (UGWS) is about $38,000 \mathrm{~km}^{3}$ in 2005 , varying from $\sim 300 \mathrm{~km}^{3}$ in Himachal Pradesh to $\sim 2100 \mathrm{~km}^{3}$ in Assam (Bhanja et al. 2019). The other states are located within this range. During the last 15 years, the depletion of UGWS across the country has been about $-0.11 \%$ per annum, with a possibility of losing a total of about $600 \mathrm{~km}^{3}(1.5 \%$ of total UGWS) of groundwater by 2020 , thereby being left with about $37,300 \mathrm{~km}^{3}$. However, these UGWS depletions of groundwater are spatio-temporally variable. The depletion is acute in northern and eastern parts of the country $(-8.47$ and -5.32 $\mathrm{km}^{3}$ /year, respectively). Overall, rapid exhaustion of UGWS has happened in Haryana, Punjab, Uttar Pradesh, Bihar, Assam, and West Bengal, which are located in one of the most prolific groundwater reservoirs of this planet. Accordingly, oriented towards achieving SDG 6; numerous governmentsupported programs have been initiated in last several years (Bhanja et al. 2017), targeted towards availability and conservation of groundwater for future India, e.g., Swatch Bharat Abhiyaan for developing better access to sanitation and decrease sanitation-borne water pollution, Har Ghar Ko Paani and Jal Jeevan Yojona for clean water supply to every Indian household by piped water supply of 55 liter per capita per day availability by 2024, and MNREGA and Atal Bhujal Yojona for rejuvenation and restoration of groundwater.

Following the WHO guidelines, improved sanitation with frequent washing of hand for at least 20 seconds, is one of the primary advisory. Inevitably, such advisory, if properly followed, would increase at least $20 \%$ per capita clean water consumption for each household, resulting to enhanced stress on availability of clean water vis-à-vis groundwater, escalating drinking water shortages. The water consumption, as well as the wastewater generation across the globe, have increased manifold due to 
multiple-time hand washing, sanitization of external or procured substances, along with our work place. Many urban areas of north and western India are suddenly exposed to an acute water crisis as the gap between water availability and supply increased to thousands of millions of liters per day. Further, in several cities and their urban hinterlands, e.g., Delhi, Mumbai, Bangalore, Chennai and areas in vicinity, lockdown-related travel restrictions have resulted in decline in tanker water supply, which is the common management strategy of seasonal increase in water demand in several, highly populated, water-stressed areas, where groundwater availability in the vicinity are limited. Even if, time-bound community water supply or limited tanker supply are available, the rush to collect sufficient water for the household, standing through hours long queues, result in inevitable flouting of social distancing, another key WHO advisory to arrest community infection. Thus, in such a water crisis situation, residents in cities, peri-urban regions and villages would be vulnerable to infection exposure without having much option, as for most of these people, securing drinking and domestic water and sustaining regular life is a much higher priority than avoiding the risk of virus transmission.

Further, on an average, only about $60 \%$ of the global residents (including Indians) had access to basic facilities of hand washing with sufficient water and soap in 2017. In some of the less developed countries, this number can be even less by $25 \%$ (UN 2020c). Thus, potentially more than 3 billion of the global population and 500 million Indians have less probability to adhere to the aforesaid health advisory. For many of these people, getting sufficient clean water for their essential daily needs in the summer times gets into jeopardy, let alone proper sanitation practices. Also, although, not delineated yet, the possibility of transmission threat through fecal waste can be yetnot understood threat. Several studies have documented the presence of the COVID-19 viral load in waste water of urban sewerage system. The possibility of contamination of these sewage to clean water through untreated discharge to surface water (e.g., rivers) or leakage, as well as possibility of supply of traditionally treated grey water (may be ineffective for the virus) as urban recycled water also pose potential transmission pathways.

This unexpected and unprecedented situation exposes a lot of uncertainty for future situations, as in post-COVID situation, the first priority for policy makers would be definitely to jump-start the economy and secure the food security and employment. This might need enhanced water usage for both industrial and agricultural sectors to increase productivity, thus further exacerbating the water availability and groundwater mining in a longer term. However, this situation also provides a silver lining for future, since this vicious situation demonstrate further need for achieving SDG 6, mostly for the developing country, through ground-level infrastructure development of access to clean water and sanitation infrastructure, as well as securing plans for sustainable use of groundwater (Mukherjee et al. 2019). Integrated water resource management policies should be employed to minimize the risk of water scarcity, along with developing for water conservation (Upadhyay 2020). Hence, scientifically-prudent, adaptive groundwater management strategies are immediately required to secure, sustain and refresh the accessible, residual, unpolluted groundwater through times of changing socio-economic needs (Mukherjee 2018; Mukherjee et al. 2020). This would need a huge public investment and incentives, which can also generate employment and lead to poverty alleviation (SDG 1).

\section{Pandemic and the water cycle}

Earth system consists of four spheres, atmosphere, hydrosphere, biosphere and geosphere and the water cycle interacts with all the four spheres. Implications of pandemic on water cycle involve complex processes mostly associated with the propagation of perturbation along the links connecting the components of the four spheres, similar to a complex network. Weather was found to be one of the factors that influence COVID-19 transmission (Tosepu et al. 2020). Studies in New York showed some correlation of the virus transmission with temperature and air quality. However, no scientific evidence was available to indicate that warm weather would influence the pandemic (Bashir et al. 2020). As for example, the world-wide lockdown has resulted in a reduction in the pollution, which may have impacts in terms of changing the incoming radiation and hence, changing the moisture transport, rainfall patterns and evapotranspiration. It also affects the anthropogenic water cycle in terms of human water use. Assessment of the same is challenging due to limited availability of datasets and the difficulty in training the model parameters under such sudden 
change. The propagations of perturbations need time and it is also important to understand the conflicting impacts of the memory of perturbation and reverse impacts of unlocking the lockdown.

The medium range to seasonal water cycle predictions considers the model parameters estimated from the past data. However, the newer environment might have resulted in a significant change in the same and real challenge lies on how to consider such resulting uncertainty in the water resources management. One of the key issues is related to disaster management. The socio-economic vulnerability of the population has been increased quite significantly over the last few months due to the pandemic and associated lockdown. Given that the hazard of a climate disaster remains the same, the risk, which is a product of hazard and vulnerability, will increase significantly. Recent incidents like the landfall of cyclone Amphan and its impacts on southern West Bengal say the same story. We are now almost at the starting of monsoon. Even if we consider that this year, we will have a normal monsoon, still it is expected to have few incidents of flood. The flood evacuation will be greatly affected by the pandemic situation. It is extremely difficult to continue the rescue operation during the pandemic by maintaining the physical distance. The other issue lies in accommodating the affected people in the flood shelters. As for example, mostly the flood shelters consider very small area per person, and this is much smaller than that is required to maintain physical distance. A single infected case in a flood shelter will result in a significant increase in the pandemic risk with a possibility of most of the other people in the shelter getting affected. Further to this, many shelters have already been converted to quarantine facilities and this has multiplicative implications on the total risk to the population.

The present challenge of the earth scientists working in water resources is to understand the trajectory of human-natural hydro-meteorological system under the pandemic scenarios and coming up with innovative solutions to achieve the conflicting objectives related to climate disaster and pandemic risk.

\section{Impact of pandemic on air quality and climate}

The World Health Organization (WHO) report in 2016 indicated that $8 \%$ of the total death in the world is due to air pollution and $91 \%$ of the world population lives in places where the air quality is very poor. The lockdowns implemented by the authorities to reduce the spread of COVID-19 pandemic improved the air quality all over the world in general and urban areas in particular. The lockdown, though did not impact domestic activities in a major way, resulted in almost total shut down of several industries, large business establishments, air traffic, rail traffic besides a near-total restriction of movement of road traffic, marine traffic and consequently a large reduction in power generation for a long period.

The Copernicus Atmosphere Monitoring Service (CAMS) observed a 20-30\% reduction in fine particulate matter with diameter less than $2.5 \mu \mathrm{m}$ $\left(\mathrm{PM}_{2.5}\right)$ over China for the month of February in year 2020 compared to the monthly averages for previous three years. Chen et al. (2020) reported that the human health benefits from the air quality improvement might have outnumbered the confirmed COVID-19 death in China.

This lockdown, for duration quite longer than the atmospheric life-time of several short-lived climate forcing agents, provided a unique opportunity to assess the role of anthropogenic emissions on air quality and climate. The lockdown-induced industrial and economic slowdown resulted in improvement of air quality across the globe. It is reported that, due to the reduction in fossil fuel based power generation and restricted transport (both surface and air), the emission of greenhouse gases and particulate matter concentration have been drastically reduced during the lockdown period. TROPOMI satellite observations by European Space Agency showed 40-50\% reduction in $\mathrm{NO}_{2}$ concentrations (major sources are power plants, industrial emissions and vehicles) over major cities over Europe, US, China and India (Delhi and Mumbai), which was never reported since the advent of satellite measurements. Recent satellitebased observations by NASA and European Space Agency documents that air pollution in some of the pandemic epicenters like, Italy, India, Spain, USA and city of Wuhan in China have reduced up to 30\% (Muhammad et al. 2020; Wang and Su 2020). Air pollution in New York and Delhi reduced by $\sim 50 \%$ from the preceding year, with substantial decrease in $\mathrm{PM}_{10}, \mathrm{PM}_{2.5}, \mathrm{CO}$ and $\mathrm{NO}_{2}$ (Mahato et al. 2020; Saadat et al. 2020). Almost a 1/3rd decrease was observed in tropospheric $\mathrm{NO}_{2}$ over southeast Asia, with significant decrease in AOD and pollution outflow over the oceanic regions (Kanniah et al. 2020). However, it is important to 
note that the reduction in $\mathrm{NO}_{2}$ concentration has resulted in an increase in surface level $\mathrm{O}_{3}$ concentration as $\mathrm{NO}_{2}$ is the major killing agent of $\mathrm{O}_{3}$ in the troposphere where it is a greenhouse gas and a pollutant. Sicard et al. (2020) reported that lockdown measures led to a decrease of $\mathrm{NO}(\sim 63 \%)$ and $\mathrm{NO}_{2}(\sim 53 \%)$ concentrations in Nice, Rome, Valencia and Wuhan, while $\mathrm{NO}$ and $\mathrm{NO}_{2}$ declined by $53 \%$ and $30 \%$ in the highly industrialized city of Turin. At the same time, the surface $\mathrm{O}_{3}$ levels increased by $24-27 \%$ in Nice and Turin, by $14 \%$ in Rome and by $36 \%$ in Wuhan (Sicard et al. 2020). Based on the analysis of data collected from 22 cities over India during March 16th to April 14th from 2017 to 2020, Sharma et al. (2020) reported a reduction of $43 \%$ and $18 \%$ in $\mathrm{PM}_{2.5}$ and $\mathrm{NO}_{2}$, respectively, while the $\mathrm{O}_{3}$ concentration increased by $17 \%$. Hence the impact assessment of lockdown calls for a combined analysis of all the constituents of atmosphere and their interactions.

The reduction in air traffic will have significant impact on the free tropospheric aerosol concentrations and hence on high level clouds. It is also important that the decrease in atmospheric emissions in the planetary boundary layer over the Asian Summer Monsoon anticyclone region (known as the gateway to stratosphere) will reduce the vertical transport of pollutants to the stratosphere, where it is expected to have a longer life time and can affect the chemistry of stratosphere and ozone layer. Reduction in aerosols also leads to enhanced amount of surface reaching solar radiation and can significantly affect the surface temperature which will have distinct climate implications over land and ocean. There were debates and discussions in the scientific community on the role of reduction in aerosol concentrations due to lockdown on recent cyclones and monsoon to follow, based on the hypothetical simulation analysis carried out in the past. The present scenario is an excellent opportunity to test their hypothesis by combining the modelling studies and the observed changes in the atmosphere due to lockdown.

However, with subsidence of the pandemic in optimistic near-future and resumption of normal industrial and transportation activities there would be definitely a reversal of the trend (Zambrano-Monserrate et al. 2020). The reduction in atmospheric emissions during lockdown for a period of few months is not expected to have a significant long term effect on future climate, though short term effect on improvement in air quality is possible. Decreasing emission of greenhouse gases for a limited period of lockdown will not provide any long term benefits in terms of cleaning up our environment or developing resilience to climate change (Zambrano-Monserrate et al. 2020). This observation provides a strong rationale for transition to alternate, pollution-free energy sources in near future and drastically reduce emissions following the Paris climate accord (Tollefson and Weiss 2015). To improve future climate, efforts are required for a consistent reduction in atmospheric emission of both long lived greenhouse gases and short lived climate forcing agents (Solberg and Akufo-Addo 2020; Srinivasan 2020). While planning the postCOVID rebuilding of economy, governments should systematically shift to a sustainable development plan that is suited for both society and earth.

\section{Post Script: Opportunity in disguise}

In an optimistic note, during this 'Decade of Action', we can collectively build a healthier, safer, environment-friendly prosperous world (Solberg and Akufo-Addo 2020). Countries which are able to push their effort in regaining the momentum in achieving the SDGs, might possibly be better placed in their recovery path from this exceptional global-scale human and economic debacle (UN 2020a). It may be envisioned that even though we have lost substantial gains in attaining the SDGs (Solberg and Akufo-Addo 2020), this pandemic provide an opportunity for us to unitedly develop an impetus to achieve the SDGs (Arora 2020; Paital 2020). Scientifically-informed, adaptive mitigation and management strategies are immediately required to secure, sustain and refresh the polluted water and air through times of changing socio-economic needs. Innovative evolution of energy generation and transportation can help to retard the climate change rates. This would need a huge public investment and incentives, which can also generate employment and lead to poverty alleviation (SDG 1).

Urgent policy measures and bold leadership would be needed to protect the most vulnerable and promote environmental sustainability (UN 2020a). This crisis further illustrate the global policy makers and leaders, the need for instituting sincere policies to remediate the feedback of environmental devastation (Srinivasan 2020). 


\section{Conclusion}

The UN had declared 2020-2030 as the 'Decade of Action' for achieving the 17 Sustainable Development Goals, tying together the thread between the natural environment (natural resources, ecosystems, pollution, climate), the economy (economic growth, jobs, living standards) and society (poverty eradication, food security, promotion of equity, gender equality, human rights, peace and justice, etc). But the unexpected public health crisis of COVID-19 might undermine this grand, global philosophy of 'One Earth, One Humankind'. It was expected to bring countries together to strive for sustainable development across the planet; however, overwhelming economic impact and regional polarization with closed borders would make it difficult to cherish the dream of a unified world.

On the same note, possibly this is the first time in last several decades that the ecosystem has re-tuned to pre-World War-II condition. Hence, this ongoing pandemic has provided an unprecedented opportunity for Earth Scientist to re-evaluate the impact of human development and consequent feedback of nature and human society in pre- and (hopefully) post-COVID scenarios. Also, the unexpected situation has provided an opportunity for policy makers to rethink and re-look (and potentially try to achieve) at the real priorities of society like access to clean water, sanitation and public health, for a developing country like India, which aspires to lead the world in next few decades. Assuming that the pandemic crisis ends in near future, the business-asusual would change and we would be living our daily life in a new-normal. The goals, expectations and achievements in these future scenarios can be quite different than the pre-COVID time period. Hope, we learn a lesson from this situation to properly define our societal priorities for impending future.

\section{Acknowledgement}

The authors acknowledge the constructive reviews of the anonymous reviewer and efficient handling of the Editor-in-Chief. The manuscript was largely benefitted by the review process.

\section{Author statement}

AM, SB, and SG conceived the idea and authored the article.

\section{References}

Arora P 2020 The impact of COVID-19 and the sustainable development goals, https://www.voicesofyouth.org/blog/ impact-covid-19-and-sustainable-development-goals.

Bashir M F, Ma B, Komal B, Bashir M A, Tan D and Bashir M 2020 Correlation between climate indicators and COVID-19 pandemic in New York, USA; Sci. Total Environ. 728138835.

Bhanja S N, Mukherjee A, Wada Y, Chattopadhyay S, Velicogna I, Pangaluru K and Famiglietti J S 2017 Groundwater rejuvenation in parts of India influenced by water-policy change implementation; Sci. Rep. 77453.

Bhanja S N and Mukherjee A 2019 In-situ and satellite-based estimates of usable groundwater storage across India: Implications for drinking water supply and food security; Adv. Water Resour. 126 15-23.

CAMS 2020 https://atmosphere.copernicus.eu/amid-corona virus-outbreak-copernicusmonitors-reduction-particulatematter-pm25-over-china.

Chakraborty I and Maity P 2020 COVID-19 Outbreak: Migration, effects on society, global environment and prevention; Sci. Total Environ., https://doi.org/10.1016/ j.scitotenv.2020.138882.

Chen K, Wang M, Huang C, Kinney P L and Paul A T 2020 Air pollution reduction and mortality benefit during the COVID-19 outbreak in China; In: The Lancet Planetary Health, https://doi.org/10.1101/2020.03.23.20039842.

Cohen A J, Ross Anderson H, Ostro B, Pandey K D, Krzyzanowski M, Künzli N, Gutschmidt K, Pope A, Romieu I, Samet J M and Smith K 2005 The global burden of disease due to outdoor air pollution; J. Toxicol. Environ. Health, Part A 68(13-14) 1301-1307.

Duttagupta S, Bhattacharya A, Mukherjee A, Chattopadhyay S, Bhanja S N, Sarkar S, Malakar P and Bhattacharya J 2019 Groundwater faecal pollution observation in parts of Indo-Ganges-Brahmaputra river basin from in-situ measurements and satellite-based observations; J. Earth Syst. Sci. 128(3) 44.

Kanniah K D, Zaman N A F K, Kaskaoutis D G and Latif M T 2020 COVID-19's impact on the atmospheric environment in the Southeast Asia region; Sci. Total Environ. 736 139658 .

Lafortune G, Woelm F, Fuller G and Marks A 2020 The SDGs, COVID-19 and the Global South: Insights from the Sustainable Development Report 2020; https://www. ipsnews.net/2020/07/sdgs-covid-19-global-south-insightssustainable-development-report-2020/.

Landrigan P J, Fuller R, Acosta N J, Adeyi O, Arnold R, Baldé A B, Bertollini R, Bose-O'Reilly S, Boufford J I, Breysse P N and Chiles T 2018 The Lancet Commission on pollution and health; The Lancet 391(10119) 462-512.

Mahato S, Pal S and Ghosh K G 2020 Effect of lockdown amid COVID-19 pandemic on air quality of the megacity Delhi, India; Sci. Total Environ. 730139086.

Muhammad S, Long X and Salman M 2020 COVID-19 pandemic and environmental pollution: A blessing in disguise?; Sci. Total Environ. 728138820.

Mukherjee A 2018 Groundwater of South Asia; Springer Nature, ISBN 978-981-10-3888-4, Singapore, 799p.

Mukherjee A, Duttagupta S, Chattopadhyay S, Bhanja S N, Bhattacharya A, Chakraborty S, Sarkar S, Ghosh T, 
Bhattacharya J and Sahu S 2019 Impact of sanitation and socio-economy on groundwater fecal pollution and human health towards achieving sustainable development goals across India from ground-observations and satellite-derived nightlight; Sci. Rep. 9(1) 1-11.

Mukherjee A, Scanlon B R, Aureli A, Langan S, Guo H and McKenzie A 2020 Global groundwater: From scarcity to security through sustainability and solutions; In: Global Groundwater: Source, Scarcity, Sustainability, Security, Solutions (eds) Mukherjee A, Scanlon B R, Aureli A, Langan S, Guo H and McKenzie A, Elsevier, ISBN: 9780128181720.

Paital B 2020 Nurture to nature via COVID-19, a selfregenerating environmental strategy of environment in global context; Sci. Total Environ. 729139088.

Pandey K 2020 COVID-19 will have severe impact on most SDGs: Report; https://www.downtoearth.org.in/news/gover nance/covid-19-will-have-severe-impact-on-most-sdgs-report72123.

Saadat S, Rawtani D and Hussain C M 2020 Environmental perspective of COVID-19; Sci. Total Environ. 728138870.

Selvam S, Jesuraja K, Venkatramanan S, Chung S Y, Roy P D, Muthukumar P and Kumar M 2020 Imprints of pandemic lockdown on subsurface water quality in the coastal industrial city of Tuticorin, south India: A revival perspective; Sci. Total Environ. 738139848.

Sharma S, Zhang M, Anshika, Gao J, Zhang H and Kota S H 2020 Effect of restricted emissions during COVID-19 on air quality in India; Sci. Total Environ., https://doi.org/10. 1016/j.scitotenv.2020.138878.

Sicard P, De Marco A, Agathokleous E, Feng Z, Xu X, Paoletti E, Rodriguez J J D and Calatayud V 2020 Amplified ozone pollution in cities during the COVID-19 lockdown; Sci. Total Environ., https://doi.org/10.1016/j. scitotenv.2020.139542.

Solberg E and Akufo-Addo N A D 2020 Why we cannot lose sight of the Sustainable Development Goals during coronavirus, https://www.weforum.org/agenda/2020/04/corona virus-pandemic-effect-sdg-un-progress/.
Sorensen J P R, Sadhu A, Sampath G, Sugden S, Gupta S D, Lapworth D J, Marchant B P and Pedley S 2016 Are sanitation interventions a threat to drinking water supplies in rural India? An application of tryptophan-like fluorescence; Water Res. 88 923-932.

Srinivasan J 2020 Pandemics and climate change; Curr. Sci. 118(8) $1147-1148$.

Tollefson J and Weiss K R 2015 Nations approve historic global climate accord; Nature News 528(7582) 315-316.

Tosepu R, Gunawan J, Effendy D S, Lestari H, Bahar H and Asfian P 2020 Correlation between weather and Covid-19 pandemic in Jakarta, Indonesia; Sci. Total Environ. $\mathbf{7 2 5}$ 138436.

UN 2020a https://sustainabledevelopment.un.org/sdg6.

UN 2020b COVID-19 likely to shrink global GDP by almost one per cent in 2020; https:/ /www.un.org/sustainabledevelop ment/blog/2020/04/covid-19-likely-to-shrink-global-gdp-byalmost-one-per-cent-in-2020/.

UN 2020c SDGs still offer best option to reduce worst impacts of COVID-19 and to recover better; https://www.un.org/ sustainabledevelopment/blog/2020/06/recovery/.

Upadhyay D 2020 Impact of Covid-19 on SDG Goal 6: Clean water and sanitation; https://timesofindia.indiatimes.com/ readersblog/sustainable-thoughts/impact-of-covid-19-onsdg-goal-6-clean-water-and-sanitation-21187/.

Wang Q and Su M 2020 A preliminary assessment of the impact of COVID-19 on environment - A case study of China; Sci. Total Environ. 728138915.

World Bank 2020 World Bank Press Release; https://www. worldbank.org/en/news/press-release/2020/05/15/worldbank-support-protect-poorest-india-coronavirus.

Yunus A P, Masago Y and Hijioka Y 2020 COVID-19 and surface water quality: Improved lake water quality during the lockdown; Sci. Total Environ. 731139012.

Zambrano-Monserrate M A, Ruano M A and Sanchez-Alcalde L 2020 Indirect effects of COVID-19 on the environment; Sci. Total Environ. 728138813. 